American Journal of Applied Sciences 9 (3): 392-398, 2012

ISSN 1546-9239

(C) 2012 Science Publications

\title{
The Evaluation of Relative Efficiency of Teaching Hospitals
}

\author{
${ }^{1}$ Fereshteh Farzianpour, ${ }^{2}$ Shayan Hosseini, \\ ${ }^{3}$ Tahera Amali, ${ }^{4}$ Shadi Hosseini and ${ }^{5}$ Sayed Shahab Hosseini \\ ${ }^{1}$ Departmentof Health Management and Economics, \\ School of Public Health, Tehran University of Medical Sciences, Tehran, Iran \\ ${ }^{2}$ Department Management of Power and Energy, Faculty of Power and Energy, \\ Amirkabir University, Tehran, Iran \\ ${ }^{3}$ Department Health Care Management, Faculty of Allied Medicine, \\ Tehran University of Medical Sciences, Tehran, Iran \\ ${ }^{4,5}$ Department Management, Faculty of Managemen, Tehran University, Iran
}

\begin{abstract}
Problem statement: The main purpose of applying practical and scientific ways to evaluate the hospital's performance and activities the optimal use of physical facilities 'technology and the present human power. One the scientific way used for this purpose is using economic analysis and tools one of which is to determining hospitals' technical efficiency the present study tries to determine the efficiency of the use of resources in teaching hospitals. Approach: The present study is a survey one. First considering the type of the research, Decision Making Units (DMUs) of teaching hospitals of Tehran University of medical Sciences was chosen. Then, considering previous similar studies and surveying the experts, input variables (1) the number of the physicians (2) the number of practicing nurse in health facilities (3) the number of active beds) and output variables (1) the number of the inpatients (2). The number of the outpatients and (3) the average length of stay) were determined and the data needed were gathered. The results of the research were examined using GAMS software and the data were analysed. Considering the society under the research the suitable model to evaluate efficiency is CCR model. The evaluation was conducted based on both in input CCR model and in output orientation approach. The results of the two methods were compared and analysed. Results: The results of the study show that the average technical efficiency of the teaching hospitals of Tehran University of medical sciences in 2010, considering variable efficiency, was $0.958 \%$ and most of the teaching hospitals $56.29 \%$ were $100 \%$ efficient. Conclusion: Efficient managers of health and treatment centres using Data Envelopment Analysis (DEA) are able through controlling efficiency and production of the hospital to reduce the cost and devote more money to developing health-treatment cares.
\end{abstract}

Key words: Data Envelopment Analysis (DEA), Decision Making Units (DMUs), Variable Return to Scale (VRS), evaluate efficiency, controlling efficiency

\section{INTRODUCTION}

Technical efficiency represents the degree to which a hospital is able to maximize the length of time the doctor spends to treat the patient, nursing care, diagnostic services and the like (Farzianpour et al., 2011a; 2011b; 2011c). Lack of the technical efficiency can be due to lack or unsuitable use of hospital resources such as personnel 'medical equipment and instruments, lack of productivity in using the entire working hours and so on (Flokou et al., 2010). The main cause of lack of efficiency is weakness in technical and executive management (Barnum et al., 2009).

Technical efficiency is defined as the ratio of output to input (Tlotlego et al., 2010):

$$
\text { Technical efficiency }=\frac{\text { Output }}{\text { Input }}
$$

In technical efficiency we deal with a combination of the data which produce certain output. Concerning this type of efficiency, the main question is if the highest degree of output is obtained considering each personnel

Corresponding Author: Fereshteh Farzianpour, Department of Health Management and Economics, School of Public Health, Tehran University of Medical Sciences, Tehran, Iran 
of health and treatment section as well as the equipment applied by the hospital? (Shahhoseini et al., 2011).

In the last decade, considering the high cost medical services due to technology development and difficulties encountered in providing enough money for most of the governments to cover the cost, policy making have admitted that health and treatment is not just a social problem but it must be examined considering economic aspects (Salek-Ardakani et al., 2009). Following these discussion, the necessity for more attention to studies on the economy of health and treatment at universities and the application of the economic theory to the field of health and treatment have been considerably emphasized.

The desirable application of human and material resources for effective production and offer of health and treatment services need awareness of economic laws.

Ever-increasing development of medical knowledge and technology and ways of treatment on one side and change of life style 'cultural and social structure, change of patterns of diseases and people's medical need, as well as rapid growth of population on the other side have caused the offering of possibilities and health and treatment services to face new difficulties and obstacles (Kirigia et al., 2010).

Moreover, considering the increasing of people's expectation of economic welfare 'demand for products and services have had an ascending trend (Emrouznejad et al., 2008). So considering limitation of resources and possibilities and ever-increasing level of products and services use 'maximum use of present possibilities is one of the most important possible solutions to decreasing the gap between demand and offer. In the present situation more profitability and efficient use of the present possibilities has practically exceeded a choice and has changed in a necessity (Karagiannis and Velentzas, 2010).

Furthermore, ever-increasing cost of health and medical services and decrease in economic growth level in developing countries have caused hospitals to be the most important element having health and treatment possibilities (Lobo et al., 2010). Hospitals have considerable ability and liability to attract financial resources and human power.

That is why in industrial countries they try through efficient management and increasing the control of hospitals' efficiency and production to decrease everincreasing costs and to devote more shares to development of health care (Chang et al., 2011).

In developing countries, the trend is reversed, that is to say hospitals due to lack of effective control over their products and dominance of inefficient managers have changed into a well that can never be filled and this leads to wastage of financial resources and humane power (Kirigia et al., 2010). In such a situation, considering deficiency of resources, adopting management strategies in order to maximize efficiency and improve activities in the area of health and treatment as well as decrease the costs is necessary to provide suitable and correct productivity of possibilities for hospitals and societies (Valdmanis, 2010). Lack of efficiency and effectiveness not only decreases the level and quality of life, but also prevents productivity in other economic sections and increases injustice and social inequality (Johnes, 2006)

Hence, it is a necessity for hospitals to address technical problems, social studies, health needs and priorities and proper allocation of the resources more than ever to decrease the costs and average length of stay and to increase the efficiency as a result of it the main motivation to apply practical and scientific ways to evaluate the hospital's performance and activities is to make the best use of physical possibilities' technology and human power. One of the scientific ways, considering this area, is the use of economic tools and analysis. One of these economic tools is to determine hospital's technical efficiency and the present study tries to determine the efficiency and productivity of resources in hospitals under Tehran University of medical sciences.

One of the effective methods when encountering mass of data and estimating them is DEA which although it has some limitations has a strong standard methodology and is clear and allows the managers to analyze a large number of inputs and outputs with different scales at the same time(AlShammari, 1999).

Evaluating the efficiency of health and treatment centers can help to considerably improve efficiency and also develop them the country. The result of the study can be an effective step to identify efficient and inefficient hospitals and to provide programs for increasing productivity for efficient hospitals under Tehran University of medical sciences.

In the present study first the technical efficiency of these hospitals from 2008-2010 was evaluated using DEA model and then the hospitals under the study were graded based on efficiency. At the end besides determining referential units for inefficient ones 'favorable inputs and outputs were determined to bring the inefficient hospitals to the level of the efficient ones.

The purposes of the present study are:

- A survey on the three-year trend efficiency of teaching hospitals under Tehran University of medical sciences 
- Determining priorities and specifying efficient and inefficient hospitals

- Specifying favorable inputs and outputs for the hospitals under the study

Data Envelopment Analysis (DEA): DEA is an excellent way to determine the Decision Making Units (DMU) efficiency degree, DEA was offered by Charnes et al. (1978) (Fig. 1-2). In this method decision making units' deficiency is calculated using mathematical models. Some inputs and outputs are defined for the DMUs and for each DMU the output and input are calculated. Then DEA models determine the study frontier providing comparison between DMUs. Each DMU which lies on the frontier is recognized as efficient DMU and DMUs which lie below the frontier are recognized as inefficient and the degree of their inefficiency is calculated based on their distance to the frontier (Cook and Zhu, 2008). DEA calculates the management ability in optimal use of existing possibilities as the efficiency score. In this method the units which use the most capacity of their resources are known as efficient unit and the rest of the units are evaluated compared with this unit (Afzali et al., 2009). In this technique first the input and output indices which show the resources used and products or services of the unit are identified and calculated then the suitable DEA is used to calculate the efficiency of the units. The feature of DEA technique is that after evaluating decision making units' efficiency, it offers corrections and improvements specific to each and in case of achieving optimal level of inputs and outputs, that unit reach optimal state. Since there are different conditions considering production atmosphere of the organizations various DEA models have been developed and each is used in a specific condition. All the models are used to evaluate the efficiency of DMUs. CCR model is a basic one for many of the other models which can be made out of CCR through suitable changes. The models are designed based on principles stated in the theory of DEA (Charnes et al., 1978):

$$
\begin{aligned}
& \max w=\sum_{r-1}^{s} u_{r} Y_{r p} \\
& \text { s.l. } \\
& \left\{\begin{array}{l}
\sum_{i=1}^{m} v_{i} x_{i p}=1 \\
\sum_{r-1}^{s} u_{r} Y_{r j}-\sum_{i-1}^{m} v_{i} x_{i j} j \leq 0 \forall j \\
u_{r}, v_{i} \geq 0 \forall i, \forall r
\end{array}\right.
\end{aligned}
$$

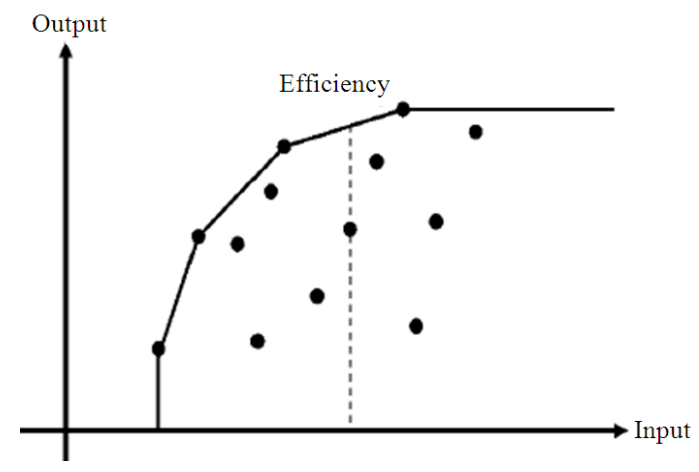

Fig. 1: (Chang et al., 2011)

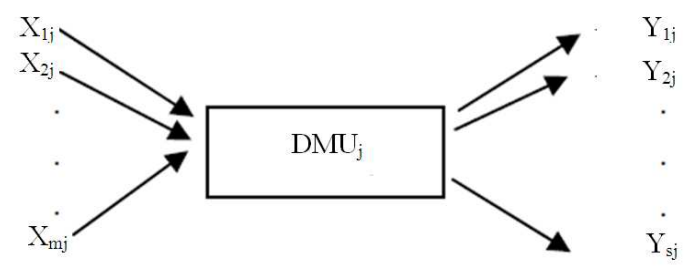

Fig. 2: (Chang et al., 2011)

Charnes, Cooper and Rhodes (CCR) Model in 1978 (Charnes et al., 1978).

$$
\begin{aligned}
X_{i j} & =(i=1,2,3 \ldots m) j \\
y_{r j} & =(j=1,2,3 \ldots s) r
\end{aligned}
$$

Various models have been developed based on DEA and each has its own competency and characteristics. The models are different regarding features such as Return to scale and Orientation or the recovery path correction (Charnes et al., 1978). From one point of view DEA models are divided into models with input quality and models with output quality.

The purpose of models with input quality is offering the recovery path through decreasing inputs and the purpose of models with output quality is designing the recovery path through increasing outputs.

Return to scale is one of the characteristics of DMUs under the study and the model chosen for evaluating efficiency must be used based on it. Return to scale can be stable or variable. Return to scale means that increase in input leads to increase with the same proportion in output. In variable efficiency the increase in output can be more or less than the degree of increase in input.CCR model is a stable return to scale one.

Banker and Morey (1986) making some changes in CCR, introduced a new known as BBC model. BBC is a DEA model which is used to evaluate the relative efficiency of units with variable return to scale. Each of 
the models should be used for special situation so that the results of the evaluation can be theoretically true. Different results can be obtained using DEA models, some of which are:

- Calculating efficiency

- Determining performance potentials

- Determining optimal degree in each index in a way that if an in efficient unit improves its situation in each index, it reaches efficiency

- Grading efficient units

- Calculating performance improvement during different periods (Banker et al., 1986)

\section{MATERIALS AND METHODS}

The present study is a descriptive-survey one. First, considering the type of the research, statistical population of decision making units of 16 teaching hospitals $(9$ specialized hospitals and 7 general hospitals) under Tehran University of medical sciences was chosen. Then, considering previous similar studies and surveying the experts, input variables (the number of the physicians, of the practicing nurses in health facilities and of the active beds) and output variables (the number of the inpatients, of the outpatients and the average length of stay) from 2008-2010 were determined and the data needed regarding the six variables, were gathered through interviewing Department of Health and Human Resources Management and Support Assistant Tehran University of Medical Sciences. After that, considering the nature of the population under the study, a suitable DEA model was chosen and then the results of the research were examined using GAMS software and the data were analyzed. To evaluate efficiency, CCR model was chosen. The evaluation was done based on both CCR model in input and CCR model in output orientation approach. At the end the results were compared and analyzed.

\section{RESULTS}

The result of the study represents the average technical efficiency of teaching hospitals under TUMS in 2010, considering the variable efficiency, was $0.958 \%$ and most of the teaching hospitals ( 9 hospitals) $56.29 \%$ were $100 \%$ efficient. Teaching hospitals (H1-H9) compared with other hospitals (H10-H16) were $100 \%$ efficient and were on the efficiency frontier (Fig. 1). They also have higher efficiency compared with other treatment units. The point which is noticeable is that the hospital number $\mathrm{H} 14$ has always been in lowest level of efficiency (in all duration of office) (Table 1). The cause of the fact is that this hospital is specialized ones and their services are distinct from others. The data showed that the mean age of the administrators in this hospital is 48.2 with a job background more than 15 years and each administrator has MSc or higher University degree. The hospital chiefs of these hospitals all were physicians in medical sciences and specialists in medical sciences, with a background of more than ten years. In this study 4998 active beds were survived. The hospital $\mathrm{H} 2$ with 1230 beds had the most and the hospital H7 with 69 beds had the fewest active beds. The model was designed with Variable Return to Scale (VRS) and based on minimizing Factors of production the main reason why the model was chosen is that the number of the patient is not under the control of the hospital and it is not possible to use a model to maximize the inputs (the number of the patients). But, considering efficiency with Variable Return to Scale (VRS) dividing technical efficiency in this model is possible.

Table 2 presents a summary of descriptive statistics (i.e., minimum and maximum input and output, means and standard deviations of inputs and outputs) for the teaching hospitals. Technical and SE score for teaching hospitals can be found in Table 3. As the table displays, out of 16 hospitals investigated in this study, nine hospitals $(56.29 \%)$ were technically and scale efficient, indicating the inputs are optimally used by these hospitals. On the contrary, the remaining seven hospitals $(43.71 \%)$ were inefficient, though all of them had a score of more than 50\%.The average TE score of inefficient hospitals was around 93\%, implying that they could reduce the use of all their inputs (since an input-oriented model is run here) by $25.47 \%$ without any reduction in the amount of their services. For example, TE of 0.50 specifically denotes that only $50 \%$ of the resources (i.e., physicians, nurses and beds) have been utilized by $\mathrm{H} 11$ to provide its current services and this hospital could reduce its inputs by $50 \%$ for providing its current services.

In accord with the argument of Ozcan (Shahhosein, 2011) the VRS efficiency scores (Table 3) were generally higher than CRS scores and thus more hospitals were considered to be efficient using this approach. As such, an average of around $0.93 \%$ for SE score of scale inefficient hospitals (Table 3) implies that there is a potential for increasing total outputs by about $0.17 \%$ via utilizing the existing capacity/ size of these hospitals. In this study it was tried to determine the quantity of inputs and outputs of inefficient hospital in order to efficiency frontier. To make the hospitals H10-H16 efficient with the input orientation model, the focus of the model is on the reduction of the quantity of inputs similar calculations were done using in the output orientation model. The results have been displayed in (Table 4). 
Am. J. Applied Sci., 9 (3): 392-398, 2012

Table 1: Estimation of technical efficiency of teaching hospitals of Tehran University of medical sciences by Data Envelopment Analysis (DEA) method in 2010

\begin{tabular}{|c|c|c|c|c|c|c|c|c|c|c|}
\hline \multirow[b]{2}{*}{$\begin{array}{l}\text { Teaching } \\
\text { Hospitals }\end{array}$} & \multicolumn{3}{|l|}{ Inputs } & \multicolumn{3}{|l|}{ Outputs } & \multicolumn{4}{|c|}{ Relative efficiency } \\
\hline & physicians & Nurses & $\begin{array}{l}\text { Active } \\
\text { beds }\end{array}$ & $\begin{array}{l}\text { Inpatient } \\
\text { bed days }\end{array}$ & $\begin{array}{l}\text { Average } \\
\text { length of stay }\end{array}$ & $\begin{array}{l}\text { Outpatients } \\
\text { visits }\end{array}$ & 2008 & 2009 & 2010 & $\mathrm{X}$ \\
\hline H1 & 20.000 & 50.000 & 105.000 & 28878.00 & 6.940 & 24045.00 & 1.000 & 1.000 & 1.000 & 1.000 \\
\hline $\mathrm{H} 2$ & 335.000 & 467.000 & 1230.000 & 255494.00 & 16.720 & 24930.00 & 1.000 & 1.000 & 1.000 & 1.000 \\
\hline $\mathrm{H} 3$ & 34.000 & 90.000 & 226.000 & 24930.00 & 9.150 & 255494.00 & 1.000 & 1.000 & 1.000 & 1.000 \\
\hline $\mathrm{H} 4$ & 25.000 & 103.000 & 211.000 & 83423.00 & 9.890 & 87308.00 & 1.000 & 1.000 & 1.000 & 1.000 \\
\hline H5 & 70.000 & 129.000 & 206.000 & 59571.00 & 8.500 & 77624.00 & 1.000 & 1.000 & 1.000 & 1.000 \\
\hline H6 & 30.000 & 118.000 & 113.000 & 19581.00 & 9.890 & 59519.00 & 1.000 & 1.000 & 1.000 & 1.000 \\
\hline $\mathrm{H} 7$ & 37.000 & 34.000 & 69.000 & 13639.00 & 11.440 & 10205.00 & 1.000 & 1.000 & 1.000 & 1.000 \\
\hline H8 & 35.000 & 99.000 & 111.000 & 28878.00 & 6.940 & 24045.00 & 1.000 & 1.000 & 1.000 & 1.000 \\
\hline H9 & 30.000 & 40.000 & 338.000 & 62341.00 & 6.830 & 70384.00 & 1.000 & 1.000 & 1.000 & 1.000 \\
\hline H10 & 330.000 & 532.000 & 530.000 & 524008.00 & 8.320 & 2500487.00 & 1.000 & 1.000 & 0.991 & 0.997 \\
\hline H11 & 4.000 & 87.000 & 108.000 & 24026.00 & 6.830 & 35384.00 & 0.845 & 1.000 & 0.905 & 0.916 \\
\hline H12 & 95.000 & 104.000 & 451.000 & 424008.00 & 2.150 & 2400487.00 & 0.852 & 0.938 & 0.999 & 0.912 \\
\hline $\mathrm{H} 13$ & 44.000 & 98.000 & 245.000 & 52341.00 & 6.870 & 60384.00 & 0.799 & 0.907 & 0.942 & 0.900 \\
\hline H14 & 28.000 & 196.000 & 460.000 & 434008.00 & 8.820 & 2500487.00 & 0.880 & 0.881 & 0.878 & 0.879 \\
\hline H15 & 55.000 & 217.000 & 399.000 & 62344.00 & 5.990 & 71384.00 & 0.835 & 0.836 & 0.922 & 0.864 \\
\hline H16 & 70.000 & 79.000 & 196.000 & 81423.00 & 5.220 & 81308.00 & 0.879 & 0.801 & 0.901 & 0.860 \\
\hline $\mathrm{X}$ & 77.625 & 152.687 & 312.375 & 136180.81 & 8.156 & 517717.18 & 0.943 & 0.96 & 0.971 & 0.958 \\
\hline & & & & 1.00 & & 8.00 & & & & 123.000 \\
\hline
\end{tabular}

Table 2: Means and standard deviations for the hospitals' inputs and outputs

\begin{tabular}{|c|c|c|c|c|}
\hline Variables & SD & $\mathrm{X}$ & $\operatorname{Max}$ & Min \\
\hline \multicolumn{5}{|l|}{ Inputs } \\
\hline physicians & 4.00 & 335.00 & 77.625 & 101.939 \\
\hline Nurses & 34.00 & 532.00 & 152.687 & 144.259 \\
\hline Active beds & 69.00 & 1230.00 & 312.375 & 284.019 \\
\hline \multicolumn{5}{|l|}{ Outputs } \\
\hline Inpatient bed days & 13639.00 & 524008.00 & 136180.810 & 171731.000 \\
\hline $\begin{array}{l}\text { Average length } \\
\text { of stay }\end{array}$ & 2.15 & 16.72 & 8.156 & 3.154 \\
\hline Outpatients visits & 10205.00 & 2500487.00 & 517717.18 & 969007.000 \\
\hline
\end{tabular}

Table 3: Technical and scale efficiency scores of the hospitals

\begin{tabular}{llll}
\hline $\begin{array}{l}\text { Teaching } \\
\text { Hospital }\end{array}$ & VRS-TE & CRS-TE & $\begin{array}{l}\text { Scale } \\
\text { efficiency }\end{array}$ \\
\hline H1 & 1.000 & 1.00 & 1.000 \\
H2 & 1.000 & 1.00 & 1.000 \\
H3 & 1.000 & 1.00 & 1.000 \\
H4 & 1.000 & 1.00 & 1.000 \\
H5 & 1.000 & 1.00 & 1.000 \\
H6 & 1.000 & 1.00 & 1.000 \\
H7 & 1.000 & 1.00 & 1.000 \\
H8 & 1.000 & 1.00 & 1.000 \\
H9 & 1.000 & 1.00 & 1.000 \\
H10 & 0.830 & 0.84 & 0.997 \\
H11 & 0.916 & 1.00 & 0.916 \\
H12 & 0.912 & 1.00 & 0.912 \\
H13 & 0.900 & 1.00 & 0.900 \\
H14 & 0.852 & 0.97 & 0.879 \\
H15 & 0.864 & 1.00 & 0.864 \\
H16 & 0.860 & 1.00 & 0.860 \\
\hline
\end{tabular}

Table 4: Input slacks for inefficient hospitals

\begin{tabular}{lcrc}
\hline $\begin{array}{l}\text { No. of } \\
\text { hospitals }\end{array}$ & $\begin{array}{l}\text { No. of } \\
\text { physicians }\end{array}$ & $\begin{array}{c}\text { No. of } \\
\text { nurses }\end{array}$ & $\begin{array}{c}\text { No. of } \\
\text { active beds }\end{array}$ \\
\hline H10 & 52.59 & 148.28 & 84.61 \\
H11 & 0.00 & 0.00 & 0.00 \\
H12 & 0.00 & 0.00 & 0.00 \\
H13 & 0.00 & 0.00 & 0.00 \\
H14 & 4.46 & 54.63 & 73.43 \\
H15 & 0.00 & 0.00 & 0.00 \\
H16 & 0.00 & 0.00 & 0.00 \\
\hline
\end{tabular}

$\overline{\mathrm{CRS}}=1 \mathrm{VRS}=1 \mathrm{SE}=$ High Hospital $=$ Efficient $\mathrm{CRS}<1$ VRS $=1$ $\mathrm{SE}=$ Low Hospital $=$ Inefficient

\section{DISCUSSION}

Analysis of the data, displayed that $43.75 \%$ of the hospitals were unable to utilize their entire resources in providing the given outputs.

These hospitals are expected, overall, DMU stands for decision-making unit, which is more appropriate term, as compared with 'firm', when studying the efficiency measurement of 'public sector organizations to reduce their inputs by an average of $22.78 \%$, to reach an efficient level. According to Kirigia et al. (2010) the presence of inefficiencies signify that hospitals have excess inputs or insufficient outputs (slacks), compared with those hospitals on the efficient frontier. Therefore, they should be reduced or augmented in input and output-orientation approach, respectively. On the contrary, if a hospital (such as H1-H9) is efficient, the slacks will be equal to zero. As an example from Table 4, an inefficient hospital such as H6 should reduce approximately 52.59 Physicians 148.28 nurses and $84 \mathrm{beds}$ out of its resources, in order to reach a level of an efficient (best practice) hospital. However, Ozcan35 has maintained that the slacks might be needed to push the hospitals to the frontier, if they could not reach the efficiency frontier, following proportional reductions in inputs (in input-orientation). H11, H12, H13, H15 and H16 exceptionally, despite being inefficient $(\mathrm{CRS}<1)$, did not have input slacks. In such situations, VRS and SE of the hospitals are advised to be attended.37 with an efficient various return to scale (VRS $=1$ ), the real cause of inefficiency and zero excess inputs could be 
associated with the low SE of these two hospitals. The highest rate of excess inputs for the inefficient hospitals is on average, concerned with their nurses and the lowest with their physicians (Table 4). These excess inputs imply that the policy-makers and managers at a provincial level, could reorganize their resources in a way that both decreases the inefficiency and reduces the cost of their hospitals. The findings also showed that the more teaching hospitals were efficiency. This could signify that the size of these hospitals in terms of the amount of their inputs seemed to have positive effects on the efficiency of the hospitals; as these hospitals had more inputs and were more advanced. Furthermore, they had some specialist departments that were a referral point for all patients in the province, which attracted more inpatient and outpatient visits. However, the teaching hospital whose efficiency scores were low. Qualitative probing might provide valuable insights and answers for these questions. This further investigation could also explain why the teaching hospital failed to achieve higher efficiency score, despite their considerably high rate of inputs. Such information as in Table 4 could also provide the authorities with valuable means to take appropriate action in line with increasing the efficiency of their organizations, proactively; either through reducing or transferring the inputs or reconsidering the use of inputs to deliver more outputs.

Drawing on the experience of this research, the researchers see value in advising the hospitals in this country and similar settings, to pay more attention to organizing and sorting their input and output data; to obtained consequently feed more accurate and reliable results into the processes of decision-making, in relation to the efficiency of their organizations this study should be envisaged as an initial step in line with efficiency measurement efforts in the country.

\section{CONCLUSION}

In the present study the efficiency of teaching hospitals under TUMS from2008-2010 was evaluated. The results of the study represent the fact that the performance of hospitals $\mathrm{H} 1-\mathrm{H} 9$ was better during these years than that of the others. In addition, the efficient inputs and outputs for the inefficient hospitals both through CCR model with input orientation and through CCR model with output orientation were determined to reach the frontier of efficiency. It is necessary for the managers of health and treatment units of teaching hospitals under TUMS, considering present limitations, to plan using each of the above mentioned methods to improve the level of their efficiency. In some of similar some external researches on evaluation of relative efficiency of hospitals only relative efficiency of those under study has been evaluated using DEA models.

But in the present study, in addition to evaluating relative efficiency, input and outputs of the purpose have been determined using both through $\mathrm{R}$ model with input orientation and through CCR model with output orientation to make inefficient units reach an efficient level. The most parts of the research was done using CCR model. Also in some studies the results have been calculated using $\mathrm{CCR}$ and BCC and then the results have been compared.

Suggestion: It is Suggestion that to Identify inefficient units in hospitals similar study be conducted for different units of hospitals in a way that different units under study be considered as decision- making units then, inputs and outputs similar to this study be evaluated and at the end, using suitable DEA models, the relative efficiency of them be evaluated.

\section{ACKNOWLEDGEMENT}

We thank the managements teams of the hospitals for allowing access to their organizations and also those members of the hospitals who kindly provided us with the data needed for the study.

\section{REFERENCES}

Afzali, H.H.A., J.R. Moss and M.A. Mahmood, 2009. A conceptual framework for selecting the most appropriate variables for measuring hospital efficiency with a focus on Iranian public hospitals. Health Serv. Manage. Res., 22: 81-91. DOI: 10.1258/hsmr.2008.008020

Al-Shammari, M., 1999. A multi-criteria data envelopment analysis model for measuring the productive efficiency of hospitals. Int. J. Oper. Produ. Manage., 19: 879-891. DOI: 10.1108/01443579910280205

Banker, R.D. and R.C. Morey, 1986. Efficiency analysis for exogenously fixed inputs and outputs. Operations Res., 34: 513-521.

Banker, R.D., R.F. Conrand and R.P. Strauss, 1986. A comparative application of data envelopment analysis and translog methods: an illustrative study of hospital production. Manage. Sci., 32: 30-44.

Barnum, D.T., S.M. Walton, K.L. Shields and G.T. Schumock, 2009. Measuring hospital efficiency with data envelopment analysis: Nonsubstitutable Vs. Substitutable Inputs and Outputs. J. Med. Syst., 35: 1393-1401. PMID: 20703515 
Chang, S.J., H.C. Hsiao, L.H. Huang and H. Chang, 2011. Taiwan quality indicator project and hospital productivity growth. Omega, 39: 14-22. DOI: 10.1016/j.omega.2010.01.006

Charnes, A., W.W. Cooper and E. Rhodes, 1978. Measuring the efficiency of decision making units. Eur. J. Oper. Res., 2: 429-444. DOI: 10.1016/03772217(78)90138-8

Cook, W.D. and J. Zhu, 2008. Data Envelopment Analysis: Modeling Operational Processes and Measuring Productivity. 1st Edn., CreateSpace, USA., ISBN-10: 1434830233, pp: 262.

Emrouznejad, A., B.R. Parker and G. Tavares, 2008. Evaluation of research in efficiency and productivity: A survey and analysis of the first 30 years of scholarly literature in DEA. Socio-Econ. Planning Sci., 42: 151-157. DOI: 10.1016/j.seps.2007.07.002

Farzianpour, F., A.R. Fouroshani, R.G. Vahidi, M. Arab and A. Mohamadi, 2011a. Investigating the relationship between organizational social capital and service quality in teaching hospitals. Am. J. Econ. Bus. Admin, 3: 425-429. DOI: 10.3844/ajebasp.2011.425.429

Farzianpour, F., M. Arab, S. Amoozagar, A.R. Fouroshani and A. Rashidian et al., 2011b. Evaluation of international standards of Quality improvement and Patient Safety (QPS) in hospitals of Tehran University of Medical Sciences (TUMS) from the Managers' Point of View. World Applied Sci. J., 15: 647-653.

Farzianpour, F., S. Aghababa, B. Delgoshaei and M. Haghgoo, 2011c. Performance evaluation a teaching hospital affiliated to Tehran University of medical sciences based on baldrige excellence model. Am. J. Econ. Bus. Admin, 3: 277-281. DOI: 10.3844/ajebasp.2011.272.276
Flokou, A., N. Kontodimopoulos and D. Niakas, 2011. Employing post-DEA cross-evaluation and cluster analysis in a sample of greek NHS hospitals. J. Med. Syst., 35:1001-1014. PMID: 20703664

Johnes, J., 2006. Data envelopment analysis and its application to the measurement of efficiency in higher education. Econ. Educ. Rev., 25: 273-288. DOI: $10.1016 /$ j.econedurev.2005.02.005

Karagiannis, R. and K. Velentzas, 2010. Productivity and quality changes in Greek public hospitals. Oper. Res., DOI: 10.1007/s12351-010-0080-4

Lobo, M.S.D.C., Y.A. Ozcan, A.C.M.D. Silva, M.P.E. Lins and R. Fiszman, 2010. Financing reform and productivity change in Brazilian teaching hospitals: Malmquist approach. Central Eur. J. Oper. Res., 18: 141-152. DOI: 10.1007/s10100-009-0097-z

Kirigia, J.M., O.A. Mensah, C. Mwikisa, E.Z Asbu and A. Emrouznejad et al., 2010. Technical efficiency of zone hospitals in Benin. Afr. Health Mon., 12: 30-39.

Salek-Ardakani, S., G. Smooha, J.D. Boer, N.J. Sebire and M. Morrow et al., 2009. ERG is a megakaryocytic oncogene. Cancer Res., 69: 46654673. DOI: 10.1158/0008-5472.CAN-09-0075

Shahhoseini, R., S. Tofighi, E. Jaafaripooyan and R. Safiaryan, 2011. Efficiency measurement in developing countries: Application of data envelopment analysis for Iranian hospitals. Health Services Manage. Res., 24: 75-80. DOI: 10.1258/hsmr.2010.010017

Tlotlego, N., J. Nonvignon, L.G. Sambo, E.Z. Asbu and J.M. Kirigia, 2010. Assessment of productivity of hospitals in Botswana: A DEA application. Int. Arch Med., 3: 27-27. DOI: 10.1186/1755-7682-3-27

Valdmanis, V.G., 2010. Measuring economies of scale at the city market level. J. Health Care Finan. , 37: 78-90. PMID: 20973375 